\title{
Trauma Surgery $\&$ Acute Care Open \\ SUNBURN: a protocol for delivering bad news in trauma and acute care surgery
}

\author{
David Velez, Andrea Gerberding, Mentor Ahmeti
}

Department of Surgery, University of North Dakota, Grand Forks, North Dakota, USA

Correspondence to Dr David Velez; david.velezjr@ ndus.edu

Received 26 October 2021 Accepted 26 January 2022

(c) Author(s) (or their employer(s)) 2022. Re-use permitted under CC BY-NC. No commercial re-use. See rights and permissions. Published by BMJ.

To cite: Velez $D$

Gerberding A, Ahmeti M.

Trauma Surg Acute Care Open 2022:7:e000851.
ABSTRACT

Introduction The delivery of bad news can be one of the most challenging tasks in surgery. There are numerous barriers specific to trauma and acute care surgery (TRACS) that make these conversations more difficult. Prior protocols have all been designed for oncology and primary care with poorer application to TRACS. The lack of guidance for leading these conversations in TRACS led us to develop the SUNBURN protocol. It draws elements from prior protocols and discards the irrelevant aspects and pays particular attention to the TRACS-specific concerns. SUNBURN protocol Step 1: S-Set Up; Step 2: UUnderstand Perceptions; Step 3: N-Notify ('Warning Shot'); Step 4: B-Brief Narrative and Break Bad News; Step 5: U-Understand Emotions; Step 6: R-Respond; Step 7: N-Next Steps.

Conclusion This protocol can provide a framework to help guide and ease the delivery of bad news in TRACS.

\section{INTRODUCTION}

The delivery of bad news can be one of the most challenging tasks in surgery. In medicine, bad news has previously been defined as 'any information which adversely and seriously affects an individual's view of his or her future'. ${ }^{1}$ Through trauma and acute care surgery (TRACS), this definition requires expansion to include not just the patient, but all those impacted by the sudden and unexpected injury or death of a loved one. Bad news from a TRACS perspective can therefore be broadly defined as information that negatively impacts one's view of the future.

There are many reasons these conversations are difficult for physicians. Despite years of advanced medical training, 60\%-90\% of physicians have had no prior formal training in the delivery of bad news. ${ }^{12}$ The process of delivering bad news can induce significant anxiety and sadness in the deliverer themselves. ${ }^{3}$ Fear of impending negative reactions as well as the physician's own feelings of inadequacy and guilt contribute to this discomfort. ${ }^{14}$ Additionally, in TRACS, the bad news will often extinguish both the patient and family's hope for meaningful recovery creating additional anxiety. ${ }^{15}$ However, as difficult as these conversations can be, the good delivery of bad news is essential.

Previous protocols in breaking bad news have explained how appropriate delivery is important for maintaining the patient-physician relationship and promoting future patient collaboration in the treatment plan. ${ }^{14-6}$ These are generally less of a factor in TRACS where there has been minimal-to-no opportunity to build rapport and the therapeutic relationship is often short lived. The delivery of bad news in TRACS, however, can still make a lasting impact and should be used as an opportunity to provide comfort and care. ${ }^{2}$ Empathetic patientcentered communication can decrease anxiety and increase physician trust. ${ }^{7}$

The most frequently referenced protocol for breaking bad news in surgery is the SPIKES protocol. ${ }^{1}$ This protocol details Setting up the interview, assessing the patient's Perception of their disease, obtaining the patient's Invitation to discuss their diagnosis, imparting Knowledge and medical information, addressing and responding to the patient's Emotions, and providing a Summary and strategy moving forward. This protocol, however, was developed at the MD Anderson and TorontoSunnybrook Cancer Centers for use in medical oncology patients, a clinical setting very different from the field of TRACS. ${ }^{1}$ Similarly, the BREAKS protocol was developed for oncology and palliative care in India. ${ }^{4}$ The ABCDE mnemonic was later developed for primary care. ${ }^{5}$ There are no identified protocols for the delivery of bad news in TRACS.

Studies exploring patient and family perspectives on the delivery of bad news have found that privacy and adequate uninterrupted time were crucial for patients and their loved ones. ${ }^{26}$ Also of high importance were clarity of the physician's language, a succinct summary of the conversation and clearly laid out next steps. ${ }^{2}{ }^{6}$ Essentially, patients and their loved ones are seeking a private and coherent conversation with an empathetic physician who highlights pertinent medical facts and places them in a context for how to move forward. The behavior perceived as most comforting and helpful is summarized as 'a caring attitude of a well-informed, sympathetic caregiver who gives families a clear message and is able to answer their questions'. ${ }^{2}$

There are numerous barriers specific to TRACS that make these conversations particularly difficult. Prior protocols have all been designed for oncology and primary care in which a patientphysician relationship has already been established. These other protocols have poorer application in TRACS, where conversations are often happening at the first interaction with no prior therapeutic relationship. Certain steps from other protocols, such as the SPIKES I-Step (obtaining the Invitation to understand how much information a patient wants to know), are less applicable. The concept they describe of 'shunning information [as] a valid psychological coping mechanism' may play a larger role with chronic disease in the outpatient setting than is permitted through acute care. Another key element not fully emphasized in other protocols is 
the 'warning shot'. Although it has previously been described, it has never been given its own step and is generally only included as a side-note in the further discussion. The 'warning shot' deserves a greater emphasis in TRACS, where the sudden nature creates a greater shock and can make information that much more overwhelming.

These patients are often younger and healthier. ${ }^{8}$ Circumstances are sudden, unexpected and often shrouded in misconception. ${ }^{8}$ For family, next steps are often unclear with significant emotional distress and patient wishes not definitively known. ${ }^{9}$ As well, these patients often present on nights and weekends in which there is less hospital staff coverage and fewer resources for grief support. ${ }^{10-12}$

The lack of guidance for leading these conversations in TRACS led us to develop the SUNBURN protocol. It draws elements from prior protocols and discards the irrelevant aspects. Particular attention is paid to the TRACS-specific concerns.

\section{SUNBURN PROTOCOL}

The SUNBURN protocol provides a framework for the delivery of bad news in TRACS. This model can be used in guiding discussions with both family or the patients themselves depending on the circumstances. It is divided into seven steps:

Step 1: S-Set Up

Step 2: U-Understand Perceptions

Step 3: N-Notify ('Warning Shot')

Step 4: B-Brief Narrative and Break Bad News

Step 5: U-Understand Emotions

Step 6: R-Respond

Step 7: N-Next Steps

\section{Step 1: S-Set Up}

The first step in delivery of bad news is the set-up. Proper preparation can significantly influence the proceeding interactions. TRACS will frequently involve emotionally charged events that can be difficult for all those involved, including the providers giving care. A physician should take time to compose themselves prior to initiating the patient/family interaction. The details surrounding the precipitating event and clinical course should be reviewed and understood. Surgeons should then mentally prepare what they want to communicate prior to initiating the conversation. Being able to clearly and concisely convey information is necessary for proper communication.

Setting should also be considered in preparation. This includes a surgeon's appearance. Blood-stained clothing can elicit needless distress and should be changed prior to the patient/family interaction. A quiet room should be selected to avoid distraction and allow total attention given to the discussions at hand. A safety strategy should also be considered. Although rare, all team members should have easy access to exit the physical space in the case of a violent reaction.

Consideration should also be given to the people present. Depending on circumstances, the presence of a consultant, such as a neurosurgeon in the case of severe traumatic brain injury, may be beneficial. Similarly, an experienced nurse can also provide excellent support and continue to provide care after the physician has left. Palliative care nurses and spiritual service personnel, if available, are particularly adept at facilitating such conversations. ${ }^{13}$

Family and friends have the ability to provide additional support as well. Through TRACS, there is often minimal-to-no opportunity to build any sense of rapport prior to delivering bad news at a first meeting. Family and friends can provide an intimate bond that no stranger can duplicate. ${ }^{14} 15$ At the same time, after an acute event, crowds have potential to grow in large numbers. Although family and friends can be supportive, excessively large groups should be avoided. Excessive crowds can prove a distraction and detract from the attention and care provided to those most directly involved. This is particularly true for pediatric traumas in which larger groups can prohibit the ability to provide direct support to parents. The ideal group size will vary based on the clinical scenario and cultural context. Optimal size should be estimated by physician discretion.

- Take a moment to compose yourself.

- Appreciate the event and clinical course.

- Mentally prepare what you will say.

- Remove any blood-stained clothing.

- Use a quiet room.

- Have a safety strategy.

- Bring an experienced nurse.

- Family/friends can be supportive but avoid excessively large groups.

\section{Step 2: U-Understand Perceptions}

Through this protocol, both step 2 and step 5 are represented by ' $U$ ' with the opportunity to understand and receive information from the patient/family. The first opportunity should be used at the very beginning of the conversation, after introducing all members of the care team present. The physician should use this time to appreciate what information is already known so that everyone is starting from the same place. Occasionally, rumors and misconceptions may have taken hold and should be dismissed before starting.

During these conversations, non-verbal behaviors should be appreciated as well. The team should sit down and avoid standing by the door as if they are in a rush to leave. They should make eye contact and look at who they are addressing. Speech with reduced rate and pitch are generally perceived as more caring and sympathetic. ${ }^{16}$ These non-verbal measures can be critical in establishing a sense of rapport with what little time there is. ${ }^{17} \mathrm{It}$ is approximated that communication is $55 \%$ non-verbal, $38 \%$ vocal and only $7 \%$ from the actual words used. ${ }^{18}$

- Introduce all of the care team present.

- Appreciate what information they already know.

- Sit down.

- Look at who you are addressing.

\section{Step 3: N-Notify ('Warning Shot')}

A 'warning shot' describes a phrase or statement that notifies the patient/family that they are about to receive bad news. Examples include phrases such as: 'I'm afraid I have some bad news' or 'I'm sorry, but the news is not good'. This should be followed by a brief pause before further delivering the bad news to allow the idea to sink in. The use of a 'warning shot' allows patients and family to brace for the impact of potentially devastating information. This forewarning is of particular importance in TRACS where the sudden nature of the event can make information that much more overwhelming.

- Give a 'warning shot' and brief pause.

\section{Step 4: B-Brief Narrative and Break Bad News}

After the 'warning shot', a simple brief narrative of what happened, only a few sentences, should be given to provide context. Excessively long narratives should be avoided and only serve to delay the final delivery. Although it may seem blunt, an overabundance of context will not soften the blow. Long 
narratives may even worsen the impact by diminishing the effect of the 'warning shot' and giving the false sense of hope.

The final breaking of the bad news should then be honest and direct. If the patient died, use the words 'dead' and 'death', avoiding euphemisms such as 'passed away'. An appropriate example would be: 'Your husband was involved in a car crash. He suffered severe injuries to his brain and heart. We did everything we could, but he died a few minutes ago.'

For patients who are alive, concentrate on the 'big picture' and avoid the inclination to catalog every injury during this initial encounter. The primary concern in these settings often consists of survival, brain damage, paralyzation and other major morbidities. Again, an overabundance of information can be overwhelming. Patients and family need time to process the key facts. An appropriate example would be: 'Your mother came in very sick. She had a large tumor in her colon that caused it to perforate. She required emergent surgery where we removed the diseased part of colon. She is now intubated in the ICU [intensive care unit]. Your mother is still in critical condition and we do not know if she will survive.'

During these conversations, it is important to avoid excessive technical information. Medical jargon can be jarring and cause confusion with misunderstanding of the clinical situation. At the same time, avoid unnecessarily gruesome detail. Although nothing should ever be hidden, if a teenage child died after resuscitative thoracotomy in the trauma bay, the parents should not be immediately subjected to those grisly details.

- Give a brief narrative for context and then deliver the news.

- Be honest and direct.

- For patients who are dead, use the word 'death' or 'dead' and avoid euphemisms.

- For patients who are alive, concentrate on the 'big picture'.

- Avoid excessive technical information.

- Avoid unnecessarily gruesome details.

\section{Step 5: U-Understand Emotions}

The second ' $U$ ' provides another opportunity to understand and receive information from the patient/family. After delivering the bad news, silence should be allowed for the facts to sink in. Emotional responses can be varied and complex. Some will fall silent whereas others will have dramatic displays of emotion such as collapsing to the ground, screaming or uncontrollably crying. Some may continue with a single emotional response whereas others will experience several phases of reaction. Provided that these reactions are non-violent and do not represent a danger to the family or staff, they should be allowed the necessary time and space to process.

- Allow for silence.

- Appreciate the emotional responses.

\section{Step 6: R-Respond}

Physicians must recognize and respond appropriately to these varied emotional reactions. These interactions should not be rushed. You should take time to validate emotions with expressions of empathy, both verbally and non-verbally. Facial tissues should be provided and available in the room. Physical contact such as holding a hand or touching a shoulder/upper back is often a warm sign of support and generally provides a natural comfort that is appreciated. ${ }^{19}$ Touching of the face, knee or thigh however should be avoided as they will most often violate the level at which a person is comfortable of comforted. ${ }^{19}$ It should also be noted that every person is different and the individual comfort level is personal. A physician should use discretion and appropriate judgment in the use of physical touch to comfort, especially in various social, religious and cultural environments.

Appropriate expressions of empathy are vital in forming rapport and giving comfort. Platitudes and expressions of false sympathy, however, often belittle emotions and should be avoided. These include statements such as 'You have another son' or 'I know what it is like'. Similarly, physicians should avoid concentrating on themselves with statements like 'I have a child too' or 'You know, this isn't easy for me'. Focus should be given solely and entirely to the patient and family. Statements of support such as 'My entire staff is here for you' or 'I'm here for you' have been shown to be the most highly rated individual statements in the delivery of bad news. ${ }^{20}$

Another large part of response is answering questions. As when the news was first given, responses should be honest and direct. Again, avoid excessive technical information and concentrate on the 'big picture'. Although many people may be left near speechless with no questions, others will react differently with a seemingly endless number of questions. The answers may not all be immediately known, but take the time to thoroughly answer every question to the best of your ability.

It is important also to focus and continue refocusing family members to the primary healthcare problems. With complex medical presentations or when numerous injuries are present, family can often become lost in the minutia; such as centering on the exact number of rib fractures in someone with a catastrophic traumatic brain injury. Concentrating on the big picture will help patients and family better comprehend a complicated medical status. It can help to avoid prolonged conversations about minor tangential medical issues that may actually confuse the family perspective more than help.

- Do not rush.

- Provide tissues.

- Appropriate physical contact can provide a natural comfort.

- Avoid platitudes or false sympathy.

- Do not concentrate on yourself.

- Provide support.

- Answer questions.

- Continue to focus on the big picture.

\section{Step 7: N-Next Steps}

Before concluding the conversation, the next steps in care should be discussed. A clear direction and strategy should be provided. In the end, patients and family should not be left in the dark, unsure of what to expect. For surviving patients, a clear plan can lessen anxiety and uncertainty.

For patients who have died, provide an opportunity for family to see the patient. Rooms should be prepared with removal of bloody linens, body preparation and covering of wounds. However, even if injuries are mutilating, family should be allowed this opportunity. This contact is an often difficult but emotionally necessary part of the grieving process. ${ }^{21}$ Families will often wonder what their responsibilities are after death. In general, there are only two potential responsibilities: calling clergy (if applicable) and contacting a funeral home which will work with the hospital to move and prepare the body. Most hospitals have social workers available to help families navigate the process, although during the weekend and nighttime hours of TRACS, they may not be available.

Finally, the 'next steps' should be considered for the medical staff. Traumatic events can cause distress not only to patients/ family, but also to the medical team providing care, known as the 'second victims'.22 After such cases, the physician should strongly 
consider a debrief with the medical team. These debriefs can improve both personal and team functioning through constructive discussions of the interventions given, things done well and possible ways to improve. ${ }^{23}$ They will enhance the professional sense of team members and add to the unity of the team. ${ }^{23}$ Traumatic events can cause considerable distress and dysfunction. ${ }^{22} 24$ Early discussions close to the event can aid in preventing the development of this stress. ${ }^{23}$

- Discuss the next steps or strategy.

- Provide an opportunity for family to see the patient.

- Responsibilities for family after death: call funeral home and call clergy.

- Debrief with the medical staff.

\section{CONCLUSION}

The delivery of bad news can be one of the most challenging tasks for practicing surgeons. Protocol-based delivery can provide support to help guide these difficult conversations. Prior protocols, however, have all been designed for oncology and primary care. There are many specialty-specific concerns in TRACS and these prior protocols have poorer application. The SUNBURN protocol includes seven steps: S-Set Up, U-Understand Perceptions, N-Notify ('Warning Shot'), B-Brief Narrative and Break Bad News, U-Understand Emotions, R-Respond and N-Next Steps. This protocol can provide a framework to help guide and ease the delivery of bad news in TRACS.

Contributors All authors contributed significantly to the creation of this article.

Funding The authors have not declared a specific grant for this research from any funding agency in the public, commercial or not-for-profit sectors.

Competing interests None declared.

Patient consent for publication Not required.

Ethics approval This study does not involve human participants.

Provenance and peer review Not commissioned; externally peer reviewed.

Open access This is an open access article distributed in accordance with the Creative Commons Attribution Non Commercial (CC BY-NC 4.0) license, which permits others to distribute, remix, adapt, build upon this work non-commercially, and license their derivative works on different terms, provided the original work is properly cited, appropriate credit is given, any changes made indicated, and the use is non-commercial. See: http://creativecommons.org/licenses/by-nc/4.0/.

\section{REFERENCES}

1 Baile WF, Buckman R, Lenzi R, Glober G, Beale EA, Kudelka AP. SPIKES-A six-step protocol for delivering bad news: application to the patient with cancer. Oncologist 2000;5:302-11.
2 Jurkovich GJ, Pierce B, Pananen L, Rivara FP. Giving bad news: the family perspective. J Trauma 2000;48:865-73.

3 Gold R, Gold A. Delivering bad news: attitudes, feelings, and practice characteristics among speech-language pathologists. Am J Speech Lang Pathol 2018;27:108-22.

4 Narayanan V, Bista B, Koshy C. 'BREAKS' protocol for breaking bad news. Indian J Palliat Care 2010;16:61-5.

5 VandeKieft GK. Breaking bad news. Am Fam Physician 2001;64:1975-8.

6 Marschollek P, Bąkowska K, Bąkowski W, Marschollek K, Tarkowski R. Oncologists and breaking bad News-From the informed patients' point of view. the evaluation of the spikes protocol implementation. J Cancer Educ 2019;34:375-80.

7 Zwingmann J, Baile WF, Schmier JW, Bernhard J, Keller M. Effects of patient-centered communication on anxiety, negative affect, and trust in the physician in delivering a cancer diagnosis: a randomized, experimental study. Cancer 2017;123:3167-75.

8 McLauchlan CA. ABC of major trauma. handling distressed relatives and breaking bad news. BMJ 1990:301:1145-9.

9 Gordy S, Klein E. Advance directives in the trauma intensive care unit: do they really matter? Int J Crit IIIn Inj Sci 2011;1:132-7.

10 Stonko DP, Dennis BM, Callcut RA, Betzold RD, Smith MC, Medvecz AJ, Guillamondegui OD. Identifying temporal patterns in trauma admissions: informing resource allocation. PLoS One 2018;13:e0207766.

11 Kieffer WKM, Michalik DV, Gallagher K, McFadyen I, Bernard J, Rogers BA. Temporal variation in major trauma admissions. Ann R Coll Surg Engl 2016;98:128-37.

12 Smith SA, Yamamoto JM, Roberts DJ, Tang KL, Ronksley PE, Dixon E, Buie WD, James MT, Care WS. Weekend surgical care and postoperative mortality: a systematic review and meta-analysis of cohort studies. Med Care 2018;56:121-9.

13 Fuoto A, Turner KM. Palliative care nursing communication: an evaluation of the comfort model. J Hosp Palliat Nurs 2019;21:124-30.

14 Axelsson AB, Zettergren M, Axelsson C. Good and bad experiences of family presence during acute care and resuscitation. what makes the difference? Eur J Cardiovasc Nurs 2005:4:161-9.

15 Labrecque MS, Blanchard CG, Ruckdeschel JC, Blanchard EB. The impact of family presence on the physician-cancer patient interaction. Soc Sci Med 1991;33:1253-61.

16 McHenry M, Parker PA, Baile WF, Lenzi R. Voice analysis during bad news discussion in oncology: reduced pitch, decreased speaking rate, and nonverbal communication of empathy. Support Care Cancer 2012;20:1073-8.

17 Mast MS. On the importance of nonverbal communication in the physician-patient interaction. Patient Educ Couns 2007;67:315-8.

18 Mehrabian A. Nonverbal communication. New Brunswick, NJ: Aldine Transaction, 1972.

19 Khan FH, Hanif R, Tabassum R, Qidwai W, Nanji K. Patient attitudes towards physician nonverbal behaviors during Consultancy: result from a developing country. ISRN Family Med 2014;2014:473654:1-6.

20 Nazione S, Nazione A, Griner T. How do perceptions of verbal statements and nonverbal actions as empathetic differ by medical appointment context? Patient Educ Couns 2020;103:410-3.

21 Chapple A, Ziebland S. Viewing the body after bereavement due to a traumatic death: qualitative study in the UK. BMJ 2010;340:c2032.

22 Seys D, Wu AW, Van Gerven E, Vleugels A, Euwema M, Panella M, Scott SD, Conway J, Sermeus W, Vanhaecht K. Health care professionals as second victims after adverse events: a systematic review. Eval Health Prof 2013;36:135-62.

23 Knobler HY, Nachshoni T, Jaffe E, Peretz G, Yehuda YB. Psychological guidelines for a medical team Debriefing after a stressful event. Mil Med 2007;172:581-5.

24 Missouridou E. Secondary posttraumatic stress and nurses' emotional responses to patient's trauma. J Trauma Nurs 2017:24:110-5. 